\title{
Person-first language: Noble intent but to what effect?
}

$\mathrm{K}$

enneth St. Louis grew up with a moderate stutter that he eventually got under control in college. His struggle with stuttering led to an interest in speech-language pathology, which he now teaches at West Virginia University in Morgantown. St. Louis is an expert in fluency disorders, including cluttering, a condition characterized by rapid speech with an erratic rhythm. Once, after a journal sent him the edited version of a paper he had submitted on cluttering, St. Louis noticed something curious.

'They changed 'clutterer' to 'person who clutters' all the way through," says St. Louis.

The changes to St. Louis' prose stem from the person-first (or people-first) language movement, which began some 20 years ago to promote the concept that a person shouldn't be defined by a diagnosis. By literally putting "person" first in language, what was once a label becomes a mere characteristic. No longer are there "disabled people." Instead, there are "people with disabilities."

No reasonable person would challenge the intent behind person-first language. Who, after all, would prefer to be known as a condition rather than as a person? But is this massive effort to change the language of disability and disease having any effect? Is it actually changing attitudes, reducing stigma or improving lives? Skeptics point to the nonexistent body of evidence. Advocates claim it starts with language and that results will follow.

Words are indeed powerful, and they can perpetuate hurtful stereotypes and reinforce negative attitudes, suggests Kathie Snow, a disability rights advocate who runs the "Disability is Natural" website (www.disabilityisnatural.com). "People with developmental disabilities have, throughout history, been marginalized and devalued because of labels," she says. "Labels have always caused people to be devalued. It has caused people to be put to death, to be sterilized against their will."

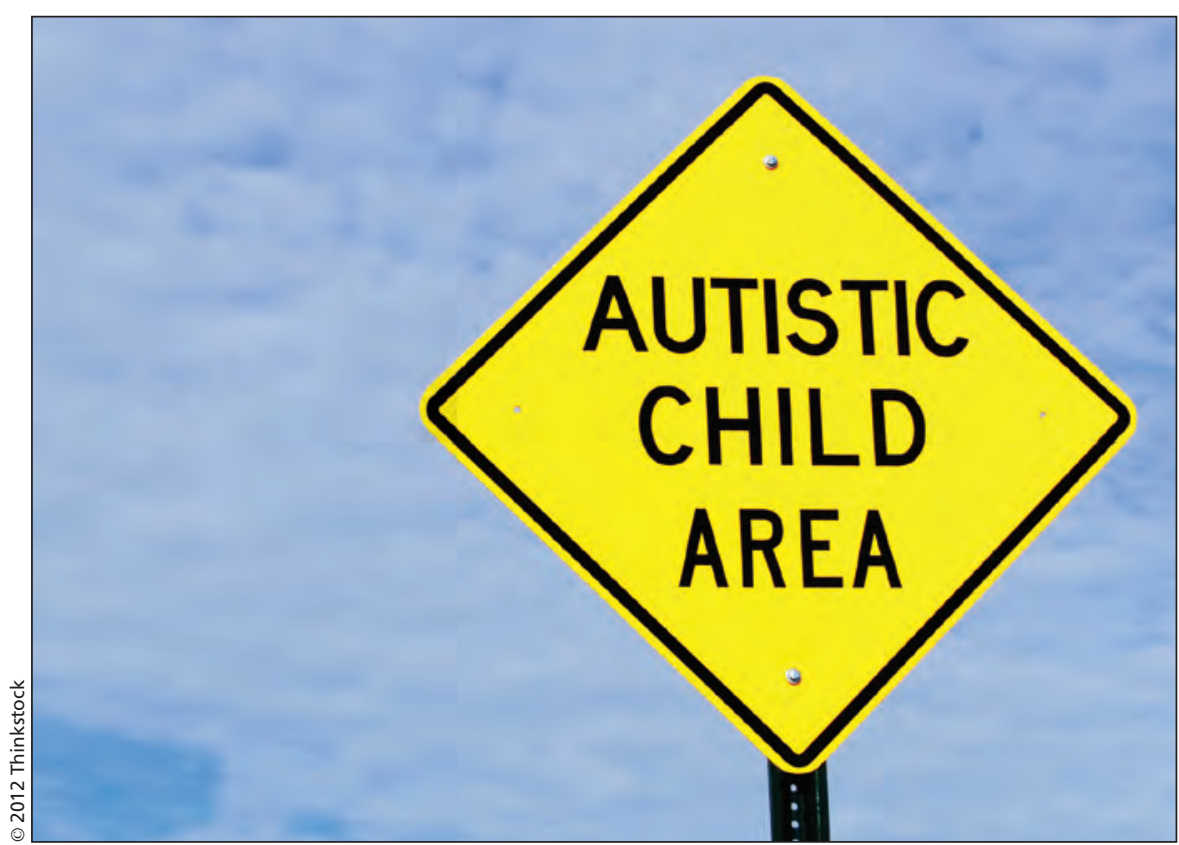

If a person-first language advocate had commissioned this sign, it would read: "CHILD WITH AUTISM AREA."

Suggesting that a diagnosis is a person's most important characteristic reinforces the all-too-common opinion that people with disabilities have limited potential and society should expect little from them, Snow has written (www.disabilityisnatural.com /images/PDF/pfl09.pdf). She suggests that the disability rights movement is changing language to be more respectful rather than merely politically correct, in a similar vein to past efforts by civil rights and women's movements.

"If people with disabilities are to be included in all aspects of society, and if they're to be respected and valued as our fellow citizens, we must stop using language that marginalizes and sets them apart," wrote Snow. "History tells us that the first way to devalue a person is through language."

The global movement to promote person-first language has been extremely successful. It is now standard in government documents around the world, as well as in scientific journals and many other publications. Widespread adoption of this grammatical structure is the reason that, present sentence excepted, this article will not refer to a stutterer, a cancer patient, a diabetic, a blind man, a deaf woman or an autistic person. It might, however, refer to a person who stutters, a person with cancer, a person with diabetes, a man who is visually impaired, a woman who is hearing impaired or a person with autism.

But some people, including members of several disability groups, aren't big fans of person-first language. They claim it is merely political correctness run amok, verbosity intended to spare hurt feelings yet accomplishing little more than turning one word into two or more words. Even worse, some suggest, tucking the names of diseases and disabilities in the shadows may have the opposite effect of what is intended. It could stigmatize words that were never considered derogatory or pejorative in the first place.

St. Louis' introduction to personfirst language made him wonder if it actually had an effect on opinions about words used to label people with various 
conditions, including speech, language and hearing disorders ( $J$ Fluency Discord 1999;24:1-24). He found that the person-first version of a label was regarded as "significantly more positive" in only $2 \%$ of comparisons. "For example," wrote St. Louis, "with the exception of widely known terms that have stigmatized individuals (e.g., 'Moron'), terms identifying serious mental illness ('psychosis') or dreaded diseases ('leprosy'), person-first nomenclature made little difference in minimizing negative reactions."

There is no evidence that person-first terminology enhances sensitivity or reduces insensitivity, notes St. Louis, and yet health professionals and schol-
The federation's main publication, the Braille Monitor, has unequivocally defended its right "to cling to its conviction that vigorous prose is a virtue and that blind people can stand to read one of the adjectives that describe them before they arrive at the noun" (www .nfb.org/images/nfb/publications/bm/bm 09/bm0903/bm090308.htm). "Blind people we are, and we are content to be described as such."

Many people with diabetes are also surprised to learn that the word "diabetic" is now considered taboo. Who turned it into a moniker non grata? Not people with diabetes, apparently. Type "diabetic" and "tattoo" into Google Images and you'll find thousands of

\section{"If you are going to be a jerk, you can be just as much of a jerk using person-first language as using the direct label." - Kenneth St. Louis}

arly publishers are now among its strongest advocates. Good luck getting your work published in a scientific journal if you don't conform. In the field of speech-language pathology, terms such as "person who stutters" or "child who stutters" have even become acronyms (PWS and CWS). To St. Louis, the notion that calling someone a PWS is more sensitive than calling them a stutterer is nothing short of ludicrous.

"It's not really about sensitivity," says St. Louis. "It's about: This is just the way it's done."

Furthermore, suggests St. Louis, the sentiment expressed in communication is far more important than the linguistic circumlocutions present in the language. "If you are going to be a jerk," he says, "you can be just as much of a jerk using person-first language as using the direct label."

Members of some disability groups have become so fed up with pressure to adopt person-first language that they have begun pushing back. The National Federation for the Blind in the United States has long opposed what it perceives as "an unholy crusade" to force everyone to use person-first language (www.nfb .org/images/nfb/publications/bm/bm09 /bm0903/bm090309.htm). people with the condition who have the word permanently inked on their skin. One of those people is Tanyss Christie, a mother of two from Chilliwack, British Columbia, who has "diabetic" tattooed on her inner left wrist in a style similar to a MedicAlert bracelet. Would she be upset if someone called her a diabetic?

"No, I wouldn't be offended," Christie writes in an email. "Diabetes is me and who I am and I don't need to hide that; I am a diabetic and have been for 29 years. I say it strong because I survived such a hard disease and hope to [for] many more years."

The topic of person-first language seems to stir particularly heated debate among people affected by autism. In general, parents of children with autism appear to prefer person-first language. Some even suggest that saying "autistic child" is not much better than referring to someone with cancer as a "cancerous person." Many adults with autism, however, believe that autism is central to their identity and prefer to use terms such as "autistic person." This has been

Person-first language implies that autism can be separated from the person, which simply isn't true, according to Jim Sinclair, an adult with autism who called identify-first language. cofounded the Autism Network International. In a widely circulated essay, Sinclair wrote that autism is such an essential feature of his being that to describe himself as a person with autism would be akin to calling a parent a "person with offspring" or calling a man a person "with maleness" (www.cafemom .com/journals/read/436505). Attempting to separate autism from personhood also "suggests that autism is something bad - so bad that it isn't even consistent with being a person."

Then there are those who take a more moderate position, varying their language according to their audience so that focus remains on their message rather than how it's delivered. This is the approach taken by Rachel CohenRottenberg, a writer who chronicles her "journeys with autism" on her blog (www.journeyswithautism.com).

"I will use person-first (i.e. person with autism) and identity-first (i.e autistic person) language interchangeably, partly for the sake of variety, and partly to resist the ideologues on both sides. I will also vary my language to suit my audience. For example, if I'm talking with people who prefer identity-first language, I will use it. If I am talking to people who prefer person-first language, I will use it. If I am talking to a mixed group, I will likely mix my terminology," Cohen-Rottenberg writes in an email. "I find that people's feelings can run so high regarding language that, even if I find person-first language very problematic, I'll use it with people who favor it so that we don't end up getting derailed into language discussions and away from the issue at hand." — Roger Collier, CMAJ

CMAJ 2012. DOI:10.1503/cmaj.109-4319

Editor's note: First of a multipart series.

Part II: Person-first language: What it means to be a "person"

(www.cmaj.ca/lookup/doi/10.1503 /cmaj.109-4322).

Part III: Person-first language: Laudable cause, horrible prose (www.cmaj.ca/lookup/doi/10.1503 /cmaj.109-4338). 